\title{
Harmonics: Rediscovering Eleutherodactylus Vocalizations ${ }^{1}$
}

\author{
Alejandro Ríos-Franceschi ${ }^{2,3,4}$ and Rafael L. Joglar ${ }^{2}$
}

\begin{abstract}
There are 17 described species of Eleutherodactylus in Puerto Rico, some more common than others. The use of harmonics as a means of vocalization has been little studied in the Caribbean. As part of a long-term study of the evolution of sonic communication in Puerto Rican Eleutherodactylus frogs, we document the use harmonics in three common but distinct Puerto Rican endemic species: E. coqui, E. antillensis, and E. brittoni. This study focuses only on the description of these vocalizations using computer software not on the behavioral implications of these vocalizations.
\end{abstract}

Key Words: Eleutherodactylus, Puerto Rico, vocalizations, harmonics

Except for Eleutherodactylus coqui Thomas, 1966, relatively little is known about the biology and natural history of Eleutherodactylus frogs in Puerto Rico (Joglar 1998). While it is common knowledge that these frogs vocalize by channeling air from their lungs through the larynx (or voice box, Deka et al. 2015), amplifying the sound in their vocal sacs, detailed quantitative analyses of their spectrograms in a comparative spatial sense are scarse. Herein, we briefly discuss the calling pattern of three common endemic Puerto Rican species of Eleutherodactylus: E. coqui, E. antillensis Reinhardt and Lutken, 1863, and E. brittoni Schmidt, 1920) (Figure 1).
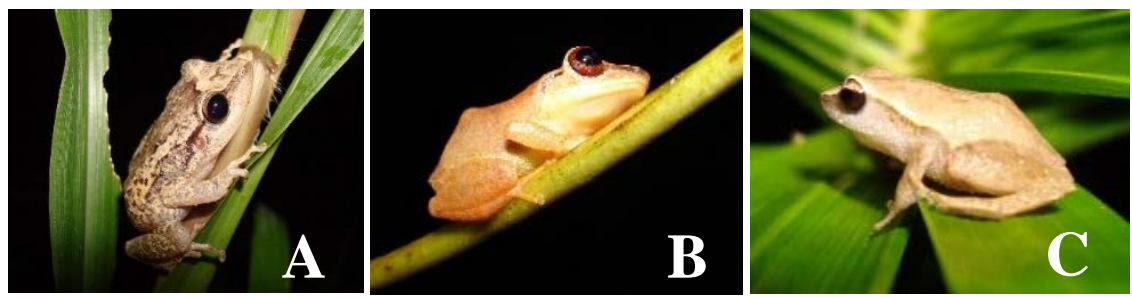

Figure 1. Images (location of vocalization and recording) of the three endemic species of Puerto Rican Eleutherodactylus mentioned in this paper. A. Eleutherodactylus coqui (Utuado, https://blaypublishers.files.wordpress.com/2018/07/eleutherodactylus_coqui_zoom0009_lr.wav) B. E. antillensis (Arecibo, https://blaypublishers.files.wordpress.com/2018/07/eleutherodactylus antillensis zoom0013 lr.wav), C. E. brittoni (Utuado, https://blaypublishers.files.wordpress.com/2018/07/eleutherodactylus_brittoni_utuado_casa-2015-09-09_18-30.wav. Photos by Alejandro Ríos-Franceschi@ .

${ }^{1}$ Received on May 22, 2018. Accepted on June 8, 2018. Last revisions received on July 15, 2018.

2 Department of Biology, University of Puerto Rico, Río Piedras, Puerto Rico 00664 USA. Corresponding authors’ e-mail: alejandro.rios1@upr.edu (ARF); rjoglar@gmail.com (RJ).

${ }^{3}$ School of Health Sciences, Sistema Universitario Ana G, Méndez, Universidad Metropolitana, Jayuya, Puerto Rico 00664 USA.

${ }^{4}$ School of Natural Sciences, Sistema Universitario Ana G. Méndez, Universidad del Turabo, Barceloneta, Puerto Rico 00617 USA.

DOI: 10.9784/LEB5(4)Rios.01

Electronically available on August 3, 2018. Mailed on August 3, 2018. 


\section{Methods}

Study Sites. Data were collected during the wet season (May-November) in 2017. Two study sites were selected due to their distinct locations (montane vs. coastal) and the three species occur sympatrically. The first study site was in Utuado; this area is mountainous with an elevation of 600 meters above sea level with an average night temperature and humidity of $25.5^{\circ} \mathrm{C}$ and $95 \%$, respectively. The second study site was in Arecibo, located near the coast with an elevation of only 12 meters above sea level and an average night temperature and humidity of $29.4^{\circ} \mathrm{C}$ and $78 \%$, respectively.

Vocalizations. To collect vocalizations, we used two different recorders. For automated field recordings, we used ARBIMON II Bio-acoustics Analysis Platform (https://arbimon.sieve-analytics.com/). The equipment was set to record for three nights (1800-0600). Additionally, we collected sound data from 50 individuals using a Zoom H6® recorder (Hauppauge, New York, USA) equipped with a shotgun microphone. Data was collected using 1 meter as the distance between the microphone and the calling frog (Meenderink et al. 2010, Narins and Meenderink 2014). From 721 recordings, the best 150 were selected for analysis using Raven Pro Interactive Sound Analysis Software ${ }^{\circledR}$ by Cornell Lab of Ornithology (Ithaca, New York, USA). By using two different recording methods we can reduce likelihood of errors caused by microphone overstimulation and creating false harmonics.

\section{Results and Discussion}

While analyzing the sound spectrogram, we noticed something special. These species can use harmonics, or notes whose pitches have a higher pitch than the lowermost or base note. Although some females such as the Túngara frog, Engystomops pustulosus (Cope, 1864), formerly known as Physalaemus pustulosus, can react to such harmonies (Ryan et al. 2010), studies in which coqui frogs are submitted to behavioral studies in which harmonics are represented are not common. True harmonic structures are not common in frog calls (Straughan and Heyer 1976). In frogs, the presence of harmonics has been shown in Odorrana tormota Wu, 1977 (Ranidae) (Narins et al. 2004, Shen et al. 2008); Adenomera hylaedactyla Cope, 1868, formerly known as Leptodactylus hylaedactylus (Leptodactylidae); Hyla gratinosa LeConte,1857 (Hylidae) (Bodnar, 1996), Leptodactylus bolivianus Boulenger, 1898 (Leptodactylidae) (Straughan and Heyer 1976). More recently, a study by Benevides and Mautz (2013), showed harmonics in the calls of the Puerto Rican common coqui, Eleutherodactylus coqui, in Hawaii. Until now, these harmonizing capabilities on E. coqui had only been mentioned by Narins 1982 . However, recent studies such as Galvis et al. (2016) suggest that harmonics in the Caribbean frogs of the genus Eleutherodactylus are not that rare and can be used to shed some light into their evolutionary relationships. 


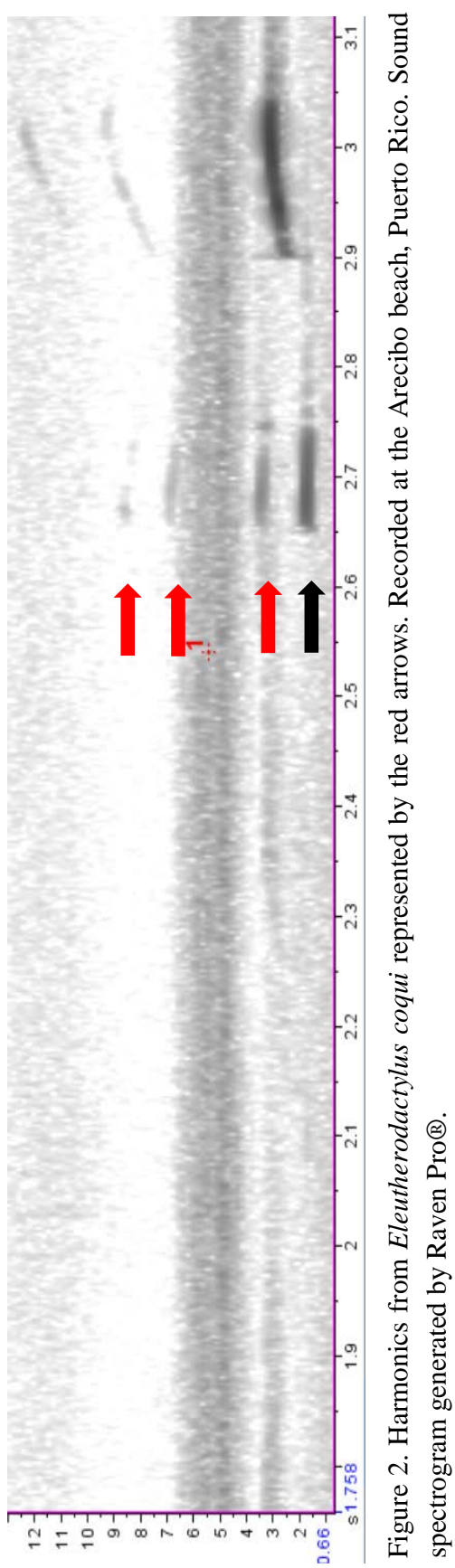


The common coqui, Eleutherodactylus coqui, produces harmonics up to approximately $12.5 \mathrm{kHz}$ (Figure 2). These signals are not in the ultrasound range ( $>20 \mathrm{kHz}$, the human ear tends to hear sounds in the range of $20 \mathrm{~Hz}$, low pitches, to $20 \mathrm{kHz}$, high pitches) but they are quite high considering that $E$. coqui males produce vocalizations between $1.8 \mathrm{kHz}-3.5 \mathrm{kHz}$ to communicate with females and to defend their territory.

Eleutherodactylus antillensis, commonly known as the Red-eyed coqui, tends to be abundant in disturbed forested areas, which can facilitate data collection. This frog has two major vocalizations: (1) the two-note call "chu-rrí" (Figure 3); and (2) the aggressive trill call ("ki, ki, ki...”) (Ovaska and Caldbeck 1997). Both vocalizations have their own specific harmonics, the two-note call has a shorter frequency range up to $6.0 \mathrm{kHz}$, Similarly, the trill call can go up to $13.1 \mathrm{kHz}$, which is almost the same frequency E. coqui has (Figure 4).

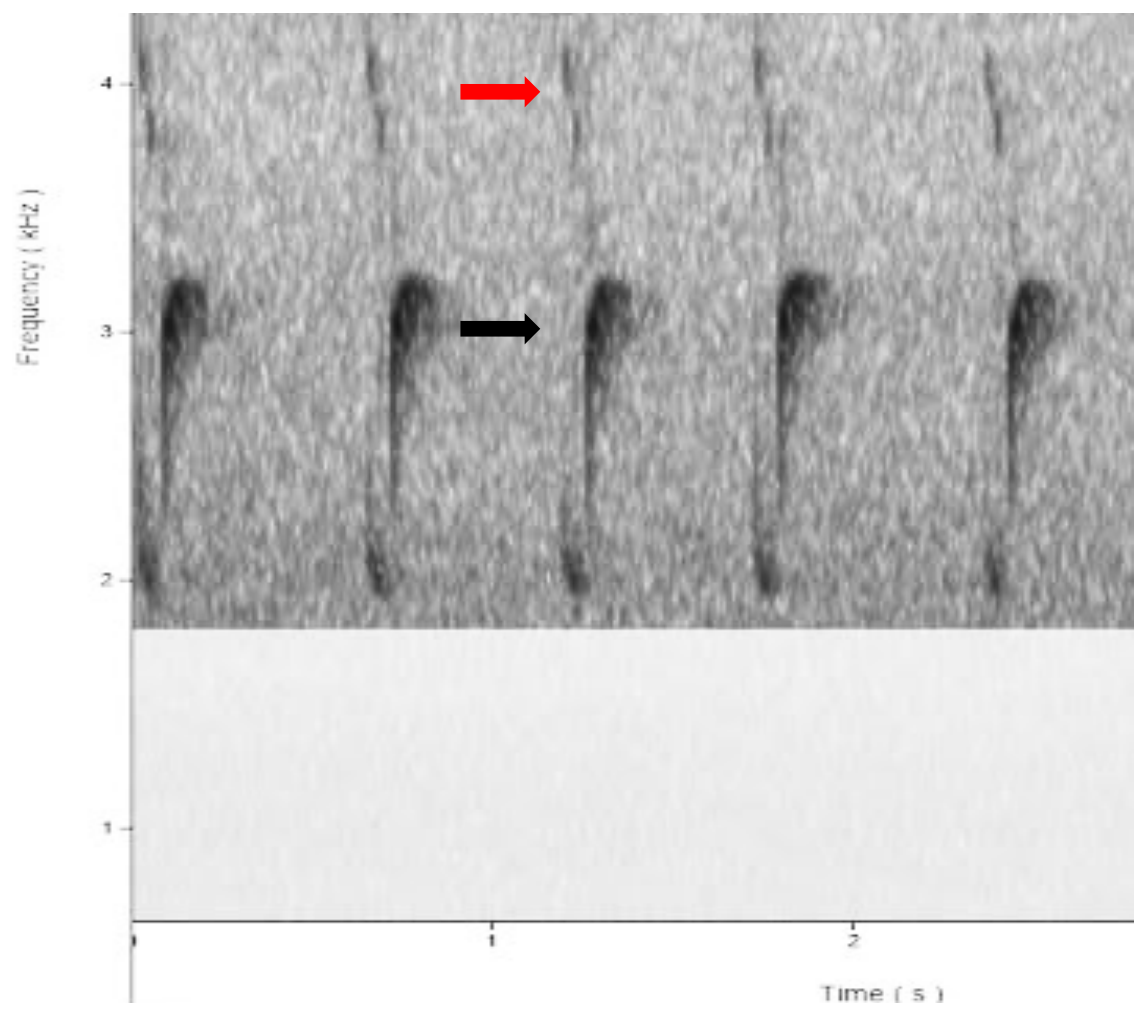

Figure 3. Eleutherodactylus antillensis vocalizations. Two-note call (“chu-“rrí”, black arrow) with one harmonic (red arrow). 


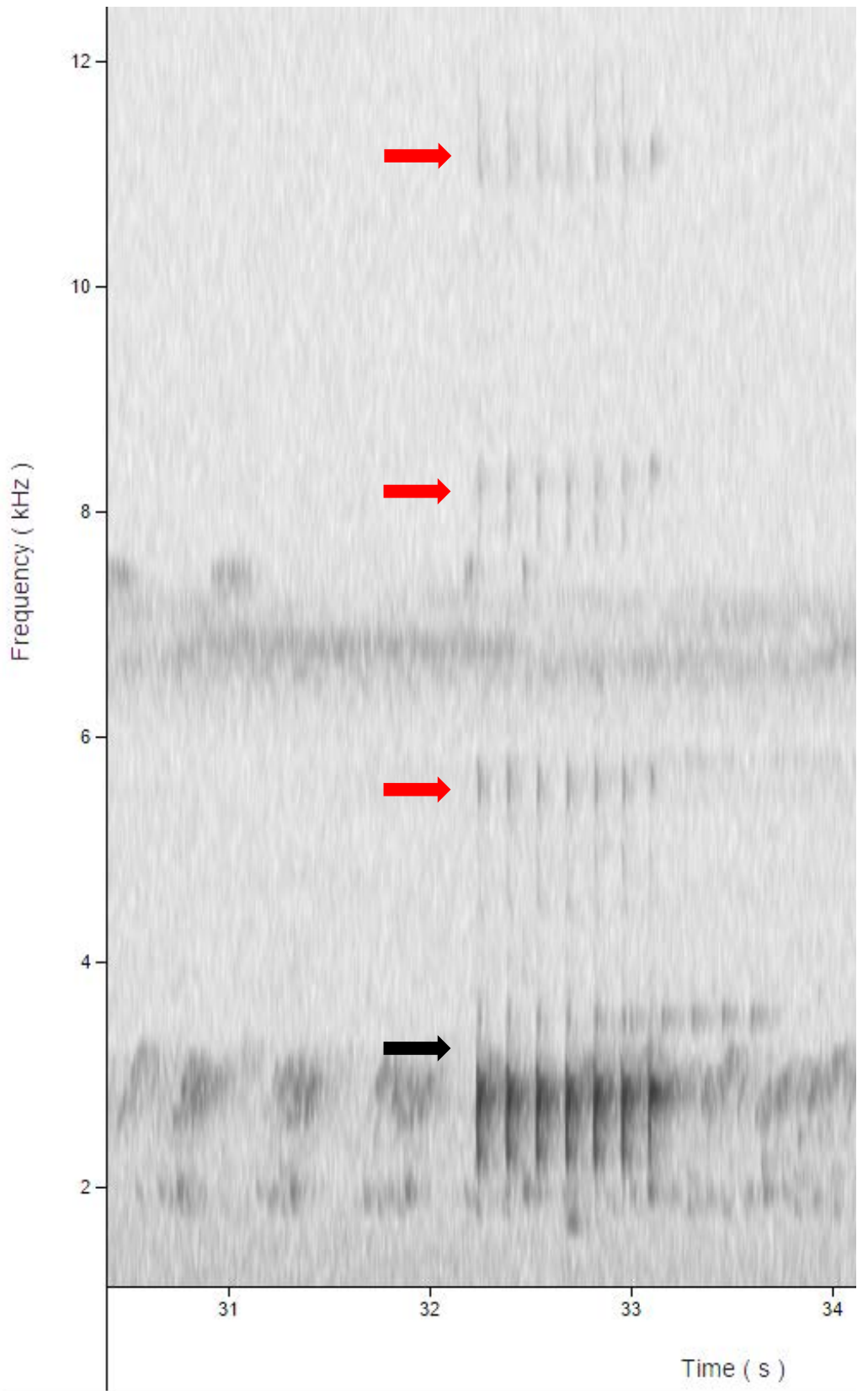

Figure 4. Eleutherodactylus antillensis vocalizations. Agresive trill call (black arrow) with three harmonics (red arrows). Sound spectrogram generated by ARBIMON II. 
Eleutherodactylus brittoni, the smallest and the least studied of the three species, has the most interesting communication system of all. This tiny frog produces pulses in a specific pattern between $3.0 \mathrm{kHz}$ and $6.3 \mathrm{kHz}(\mathrm{N}=10)$, repeating itself two to three times before starting with the two-pulse call (Figure 5). Even though Ríos-López and Villanueva-Rivera, 2013, showed this species spectrogram, they focused in partitioning of acoustic environment, rather than their behavioral pattern component. These patterns were not known until now and their functional significance, if any, is unknown.

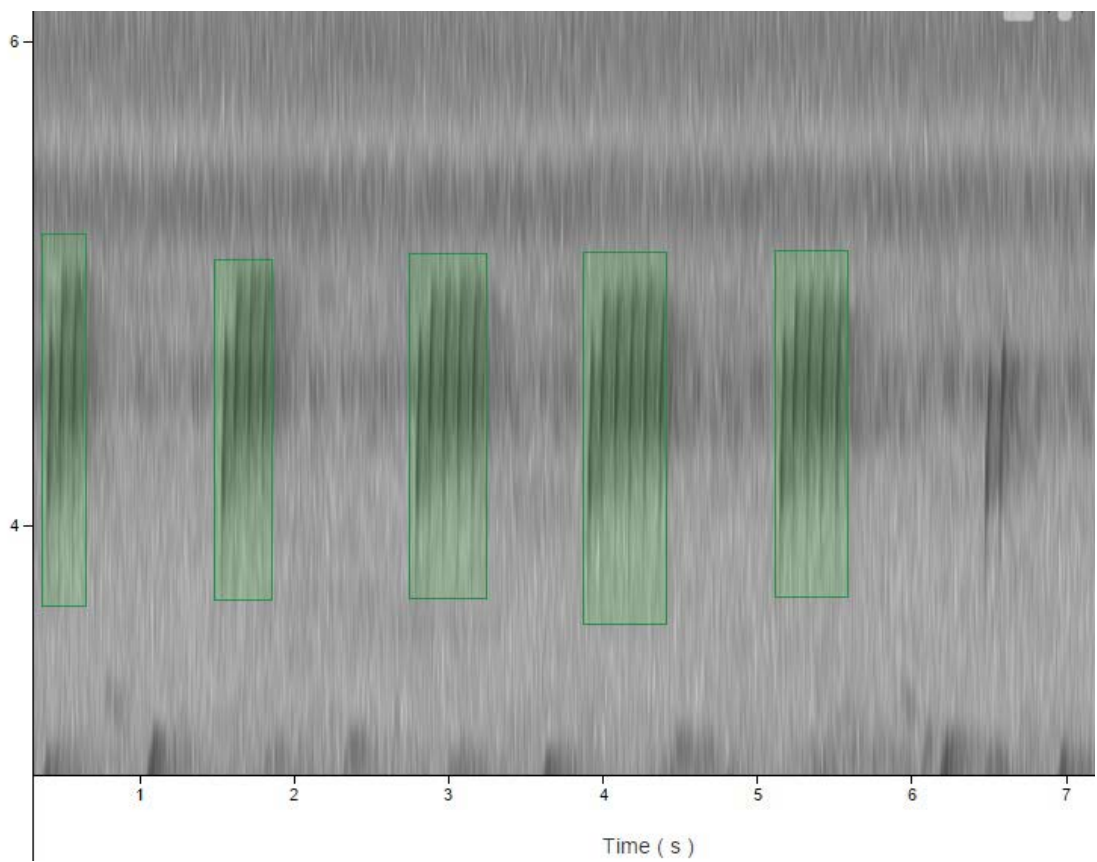

Figure 5. Sound spectrogram from Eleutherodactylus brittoni. Note patterns are denoted by the green squares $(* *, * * *, * * * *, * * * * *, * * * * * *, * * * * *$, repeat). Asterisk (*) represent pulses. Sound spectrogram generated by ARBIMON II. 


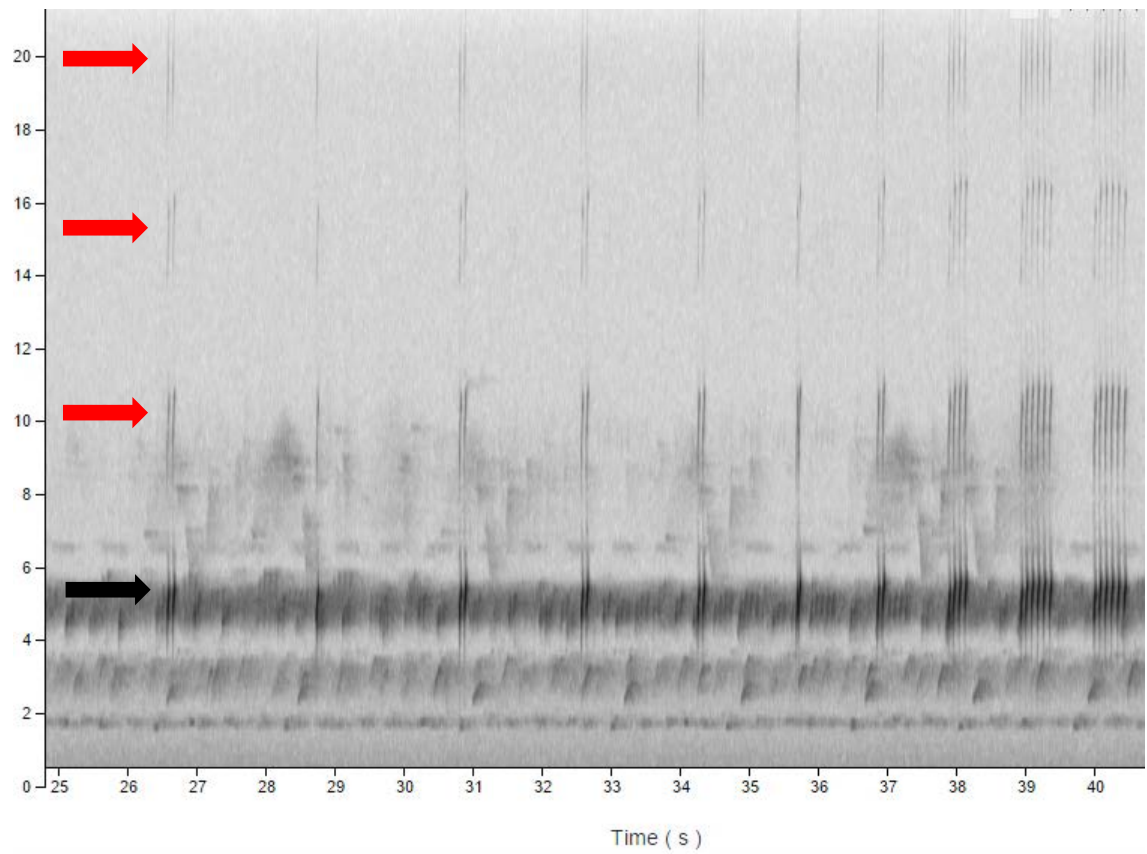

Figure 6. Harmonics (Red) shown in ARBIMON II from Eleutherodactylus brittoni ranging from $3.3 \mathrm{kHz}$ to $22.0 \mathrm{kHz}$.

Furthermore, males generate harmonics extending above $22.0 \mathrm{kHz}$, well in the ultrasound realm (Figure 6). It is not clear what is the functional significance of these ultrahigh vocalizations. But some species use them to avoid masking by background noise (Feng et al. 2006), and some species, such as Hylarana taipehensis (Van Denburgh, 1909), formerly known as Rana taipehensis, seem to use high intensity calls also, to cope with noisy environments (Sun and Narins 2005).

More research on the vocalization complexities of Eleutherodactylus may shed light into these unanswered vocalization mysteries. For now, however, when we hear (or detect) the sounds of tropical frogs, we could consider that they may not just be vocalizing a melody; they could also be generating harmonics. These data are part of an ongoing research in which these parameters are being scrutinized to further understand how these organisms communicate. By studying their auditory papillae and larynx we can better understand how these sounds are produced and how they are received by their conspecific.

\section{Acknowledgments}

We thank, Fabio Lugo, Carlos Germosen and Bianca Arzuaga (undergraduate students, University of Puerto Rico) for all their help in the field. We also thank Vivianette Figueroa-Santos, Miguel García (Caribbean Landscape Conservation Cooperative), and seven other (anonymous) colleagues for reviewing and improving the manuscript. 


\section{Literature Cited}

Benevides Jr., J. R. and W. J. Mautz. 2013. Temporal and spectral characteristics of the male Eleutherodactylus coqui two-note vocalization in Hawaii. Bioacoustics 23(1):2938. https://doi.org/10.1080/09524622.2013.805308

Bodnar, D. A. 1996. The separate and combined effects of harmonic structure, phase, and FM on female preferences in the barking treefrog (Hyla gratiosa). Journal of Comparative Physiology 178(2):173-182. https://doi.org/10.1007/BF00188160

Deka, E. Q., L. Su'ut, H. A. Wahid, and R. Zainudin. 2015. Vocal apparatus structure of the Sarawak Frogs (Amphibia: Anura: Ranidae). Sains Malaysiana 44(9):1289-1299. https://doi.org/10.17576/jsm-20154409-11

Feng, A. S., P. M. Narins, C. H. Xu, W. Y. Lin, Z. L. Yu, Q. Qiu, and Z. M. Xu. 2006. Ultrasonic communication in frogs. Nature Letters 440:333-336. https://doi.org/10.1038/nature04416

Galvis, P. A., V. Zaffaroni Caorsi, S. J. Sánchez-Pacheco, and M. Rada. 2018. The advertisement calls of three Eleutherodactylus species from Hispaniola (Anura: Eleutherodactylidae). Bioacoustics 27(1):112. https://doi.org/10.1080/09524622.2016.1260053

Joglar, R. L. 1998. Los Coquíes de Puerto Rico: Su Historia Natural y Conservación. Editorial de la Universidad de Puerto Rico. San Juan, Puerto Rico. 232 pp.

Meenderink, W. F. S., M. Kits, and P. M. Narins. 2009. Frequency matching of vocalizations to innerear sensitivity along an altitudinal gradient in the coqui frog. Biology Letters (2010) 6:278-281. https://doi.org/10.1098/rsbl.2009.0763

Narins, P. M. 1982. Effects of masking noise on evoked calling in the Puerto Rican Coqui (Anura: Leptodactylidae). Journal of Comparative Physiology 147(4): 439-446. https://doi.org/10.1007/BF00612008

Narins, P. M., A. S. Feng, W. Lin, H. U. Schnitzler, A. Denzinger, R. A. Suthers, and C. Xu. 2004. Old World frog and bird vocalizations contain prominent ultrasonic harmonics. Journal of the Acoustical Society of America 115(2):910-913. https://doi.org/10.1007/BF00612008

Narins, P. M, and S. W. F. Meenderink. 2014. Climate change and frog calls: long-term correlations along a tropical altitudinal gradient. Proceedings of the Royal Society 281(1783):20140401. https://doi.org/10.1121/1.1636851

Ovaska, K. E. and J. Caldbeck. 1997. Vocal behavior of the frog Eleutherodactylus antillensis on the British Virgin Islands. Animal Behaviour 54:181-188. http://dx.doi.org/10.1006/anbe.1996.0414

Ríos-López, N. and L. J. Villanueva-Rivera. 2013. Acoustic characteristics of a native anuran (Amphibia) assemblage in a palustrine herbaceous wetland from Puerto Rico. Life: The Excitement of Biology 1(2):118-135. https://doi.org/10.9784/LEB1(2)Rios.04

Ryan, M. J., X. E. Bernal, and A. S. Rand. 2010. Female mate choice and the potential for ornament evolution in túngara frogs Physalaemus pustulosus. Current Zoology 56(3):343-357.

Shen, J. X., A. S. Feng, Z. M. Xu, Z. L. Yu, V. S. Arch, X. J. Yu, and P. M. Narins. 2008. Ultrasonic frogs show hyperacute phonotaxis to female courtship calls. Nature Letters 453:914-917. https://doi.org/10.1038/nature06719

Straughan, I. R., and W. R. Heyer. 1976. A functional analysis of the mating calls of the Neotropical frog genera of the Leptodactylus complex (Amphibia: Leptodactylidae. Papéis Avulsos de Zoologia 29(23):221-245.

Sun, J. W. C. and P. M. Narins. 2005. Anthropogenic sounds differentially affect amphibian call rate. Biological Conservation 121:419-427. https://doi.org/10.1016/j.biocon.2004.05.017 